\title{
People's Reflections in the City: Exploring the Painting Practices of Figurative Expressionism by Academic Research
}

\author{
Assistant Prof. Dr. Mohammed Baker Mohammed Al-Abbas (Corresponding author) \\ The University of Jordan, School of Art and Design, Department of Visual Arts \\ m.alabbas@ju.edu.jo,mohdbaker83@hotmail.com,mohdbaker83@gmail.com \\ Rawan Mustafa Khaleel Abu Hammad \\ Independent Researcher in Information and Communication Technologies \\ rawanabuhammad1991@gmail.com \\ Fatima Mahmoud Mohammad Al-Tawalbeh \\ The University of Jordan, School of Art and Design, Department of Visual Arts \\ f.tawalba@ju.edu.jo,fatima_t83@yahoo.com \\ Dr. Mariana (Mohammed Amin) Mahmoud Al-Alawneh \\ Independent Researcher in Vocational Technologies and Methodologies \\ alawnehmariana8@gmail.com
}

Associate Prof. Dr. Yahya Salim Suleiman Issa

The University of Jordan, School of Art and Design, Department of Theater Arts dryahya_bashtawi@yahoo.com

Assistant Prof. Dr. Naser Yousef Ahmad Jawabra

Palestine Polytechnic University, Collage of Admin. Science and Informatics, Multimedia department njawabra@ppu.edu,nsr_obstract@yahoo.com

\author{
Abed Farhan Obed \\ Scientific College of Design, Fine Arts Department and Ph.D. Candidate in Fine Arts Studios, Faculty of Art \\ Computing and Creative Industries, Sultan Idris Education University \\ abedobed32@gmail.com \\ Rao Tahir Anees \\ Ph.D. Candidate in Management, Limkokwing University of Creative Technologies \\ aneesrao82@gmail.com
}

This paper is a practical outcome of a multidisciplinary research project conducted by the authors on the contemporary and modern practices of the Improvisation in Arts. All the authors are research-oriented practitioners in the fields of visual arts, performance arts, multimedia, Information and communication technologies as well as vocational training. Furthermore, the drawings, paintings, and sketches are all made by the correspondent author Assistant Professor Dr. Mohammed Baker Mohammed Al-Abbas as part of his research-oriented artistic practice through the hybrid painting techniques.

\begin{abstract}
The present studio-based paper aims to explore the creative reflections of the aesthetics of otherness within the practical phases of the painting production. This paper represents an experimental endeavor to create a twodimensional artwork, which is a hybrid painting technique on canvas with mixed media and acrylic paints. Within such a specific practice-based context, each phase of this practical approach outlines a critical significance from the first phase of creating that painting to the completing phase. The practical methodology is the tool that converts the researcher's/artist's vision into creative academic production. The process of creating the painting on the canvas is the methodology; such manner turns to be a primary reference for the present exploration. There is a significant paradigm in this approach, which focuses on the artwork as a morphological creature being created by the researcher/artist rather than a consequent result that only exists as a finished/complete/polished outcome. The outcome of this research is the record of the artwork production itself. This record presents visual references of the artwork progress as well as a textual reflective narrative to describe
\end{abstract}


this process with written words. This research-oriented artistic attempt introduces the artists and researchers in the domains of the Fine Arts to integrate the process of art-making into the methodologies of academic research. It is an academic text, reflective text as well as sequential images recording the artwork making. This studiobased experimentation is significant because it examines the aesthetics of the otherness into the expressive figurative abstraction in painting. Furthermore, the impact of such a studio-based approach manifests on advancing applications of the artistic oriented research in the field of Fine Arts globally on curatorial and academic levels.

Keywords: Contemporary Art Practice, Studio-Based Methodology, Practice-Based Research, Hybrid Painting Techniques, Multimedia, Mixed media, Photography

DOI: $10.7176 / \mathrm{JEP} / 11-10-08$

Publication date: April $30^{\text {th }} 2020$

\section{Introduction}

As the process of producing an expressive painting artwork is ongoing, the present practical paper utilizes studio-based experimental methodology to proceed through different phases to record the authentic painting experiment addressed and investigated through this paper (Borgdorff, 2011; Savin-Baden and Wimpenny, 2014; Gray and Malins, 2004). The research-oriented artist/author assembles the pictorial composition of the painting over a series of sequential images illustrating the progressive painting process. Furthermore, the figurative expressionist style documented throughout this paper critiques the otherness aesthetics that evokes the urban spaces of the contemporary city. The theme of the urban spaces of the city manifests throughout this painting, which represents a morphological fusion between the figurative human form and the abstract architectural form of the city spaces and details. In a parallel context, the author/artist depicts through a reflective written text the temporalities of the visual creation of the painting pictorial composition. In this regard, the paper identifies two creative actions and integrates them. The first creative action, which is the primary reference of this paper, is the creative action of creating the painting itself. Parallel to this is the creative action of reflective writing, which is a descriptive, critical, and narrative text that renders the visual temporality into a textual significance.

To identify the main aesthetical framework of this paper, which is the pictorial composition, the author/artist introduces it as the architectural system in the art of painting. As the present investigation is progressing, the dynamics of well-balanced composition are the outlines of aesthetical construction into the artist's abstract figurative painting style (Krausse, 1995). In this paper, the research-oriented artist approaches the art of painting to record and document visual inquiry and experimentation. This approach reflects kinetically the narratives of the colors and spaces revealing the details of the artistic practice. This creational process mirrors the visual temporality and the manifestations of otherness aesthetics. Such a traversing vision of the city image constructs a powerful expression into the painting's surfaces, into which the abstract representation of the figures turns to be a dynamic expressive phenomenon. The spirit of this experimentation manifests great tendencies towards the paradigms of well-balanced composition while representing the structural principles in urban details of the city with dynamic visual sensations and impressions.

\section{The studio-Based methodology: A Dynamic Manner of Assembling Knowledge and Art}

As the current studio-based exploration is ongoing, the research-oriented artist/author practices a practical methodology. Such a practical approach progresses through the performance of making art (Figurative Expressionism) as well as the performance of recording (Reflective Academic Writing). This approach is significant and meaningful because it synthesizes the art practice into academic research to authentically document the artistic and subjective manners of the art-making. The literature of Fine Arts lacks such a synthesis between the practical and reflective practices on institutional levels (Borgdorff, 2011; Savin-Baden and Wimpenny, 2014; Gray and Malins, 2004). This methodological synthesis converges the artwork with the academic writing process, into which the research turns to be a creative based exploration (studio-based artistic research). Such a constructive approach to academic writing and artistic experimentation incorporates theoretical, aesthetical, educational, historical conceptions with the active creation of the art of painting (Borgdorff, 2011; Savin-Baden and Wimpenny, 2014; Gray and Malins, 2004). Such a synthesis of an artistic manner marks the memories and imaginations of the hyper-creative person in the present artwork-based paper. Through which, a traverse and advancing visual culture crystallize into the aesthetic and academic proportions of the painting and writing, a dynamic manner of assembling knowledge and art. 


\section{The Artwork: People's Reflections in the City}

The current part of this paper presents, in pictures, the progression of making the artwork People's Reflections in the City, it is the actual process of producing a painting on 90 X 90 centimeters canvas with mixed media and acrylic paints, which is a hybrid painting technique. This part proceeds from recording the artwork making, in sequential images, to discuss the visual aesthetics of the artwork through reflective written text. This text describes the aesthetic dynamics of artistic practice, the subject of this paper.
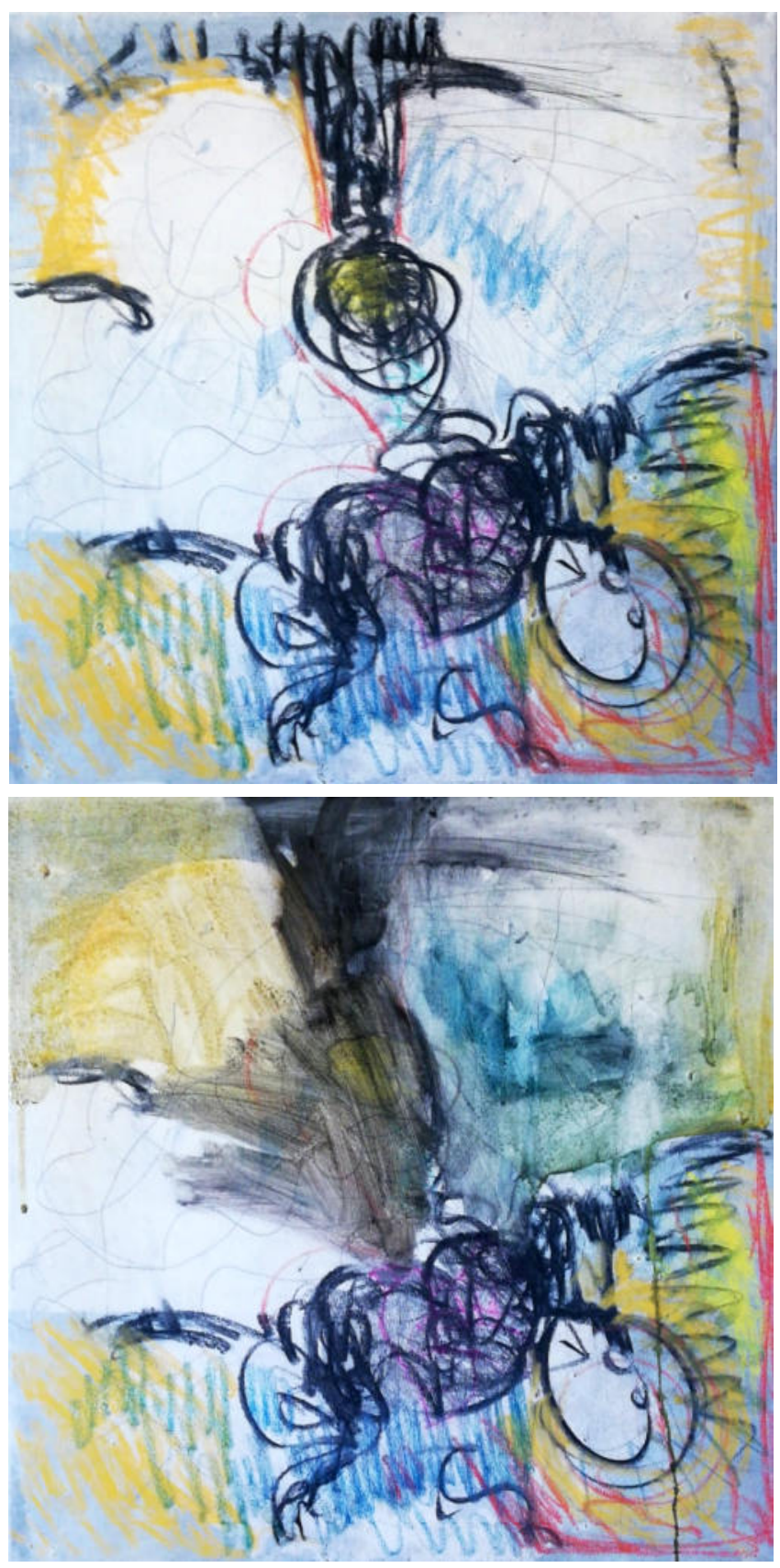

Figure 1. The Initial Painting Composition, hybrid technique and mixed media on $90 \mathrm{X} 90 \mathrm{~cm}$. canvas 

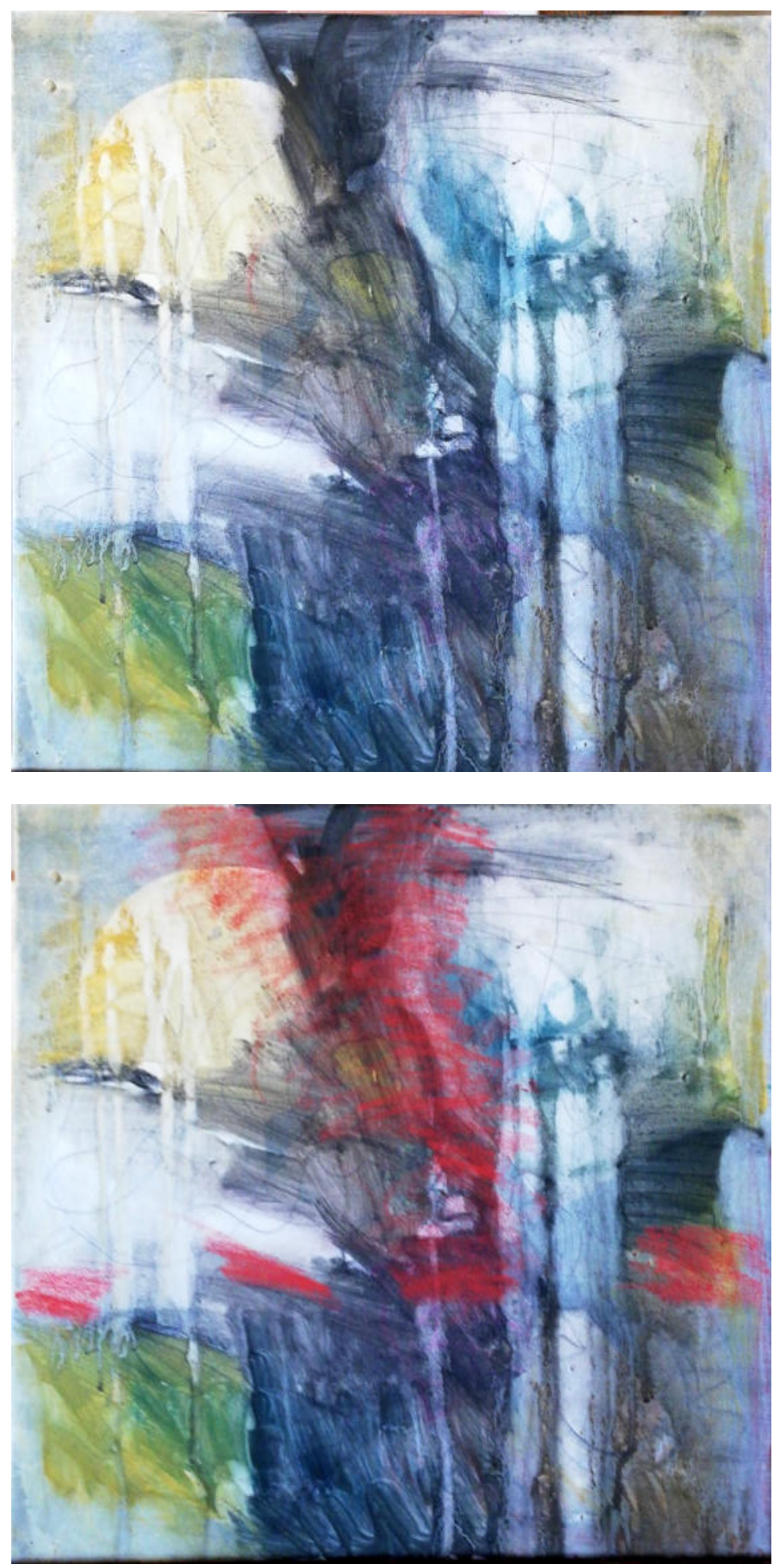

Figure 2. The Initial Painting Composition, hybrid painting and mixed media on 90 X $90 \mathrm{~cm}$. canvas. 

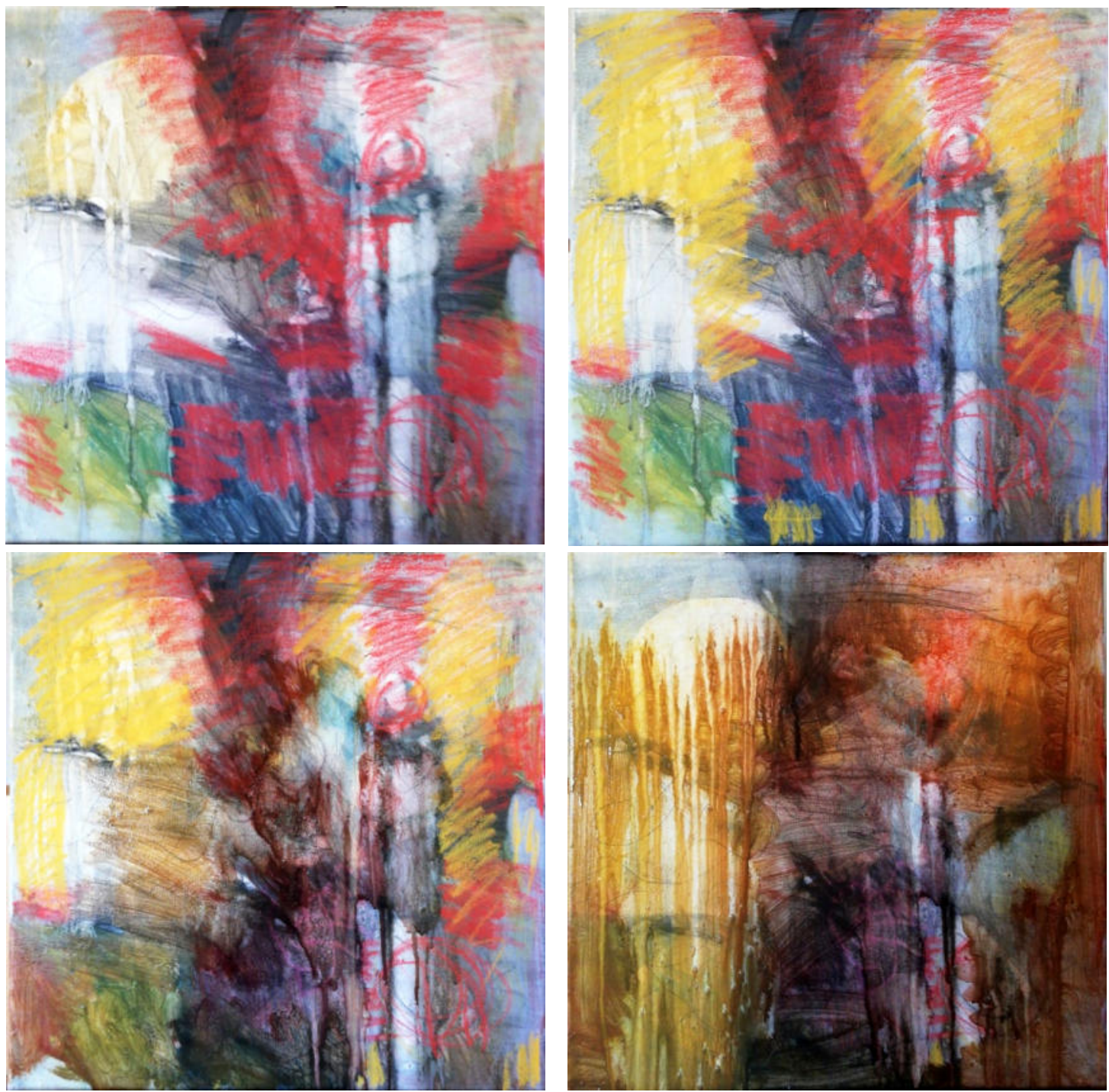

Figure 3. Composing the Color Masses across the Canvas. 

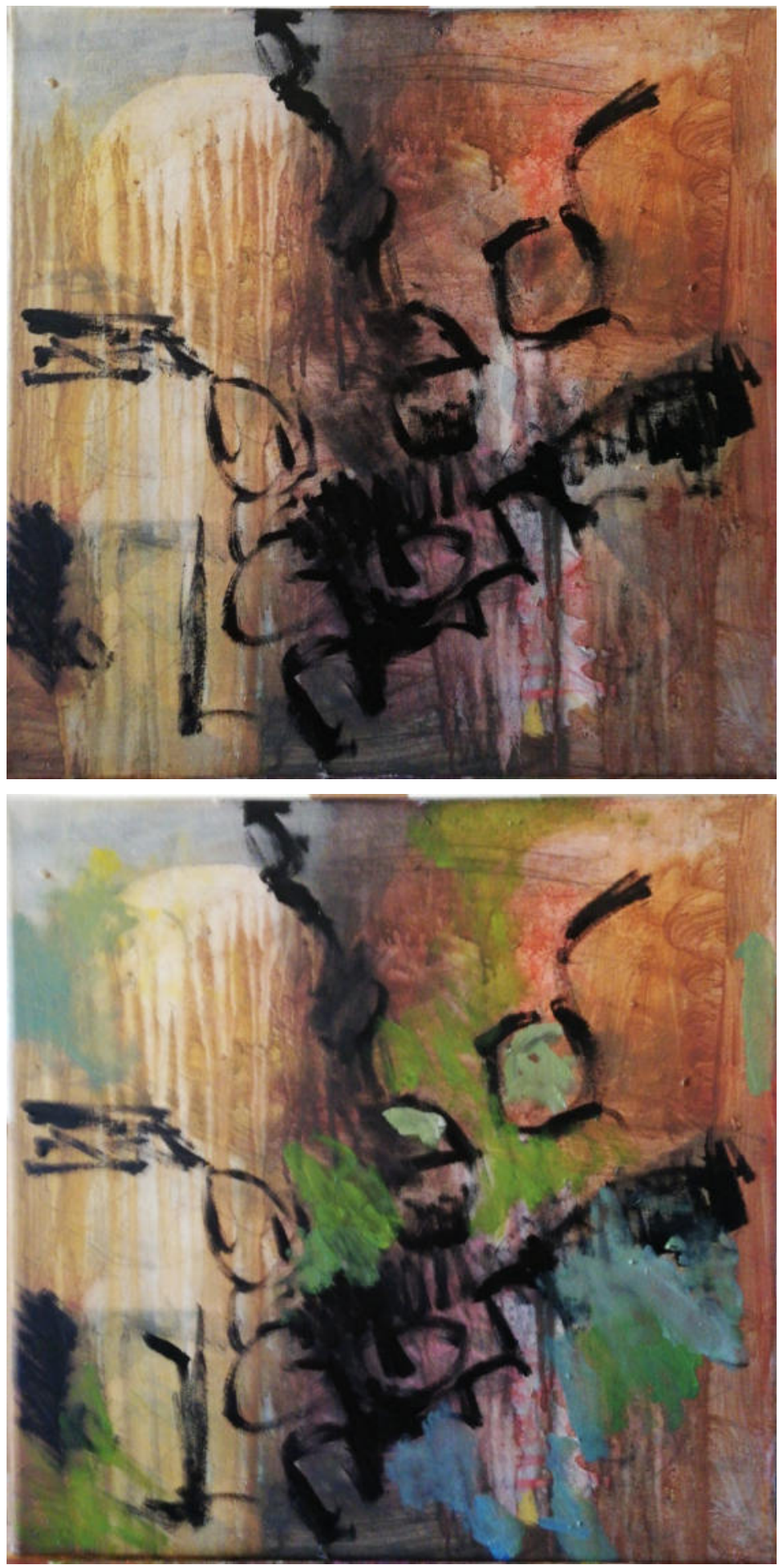

Figure 4. Composing the Color Masses across the Canvas 


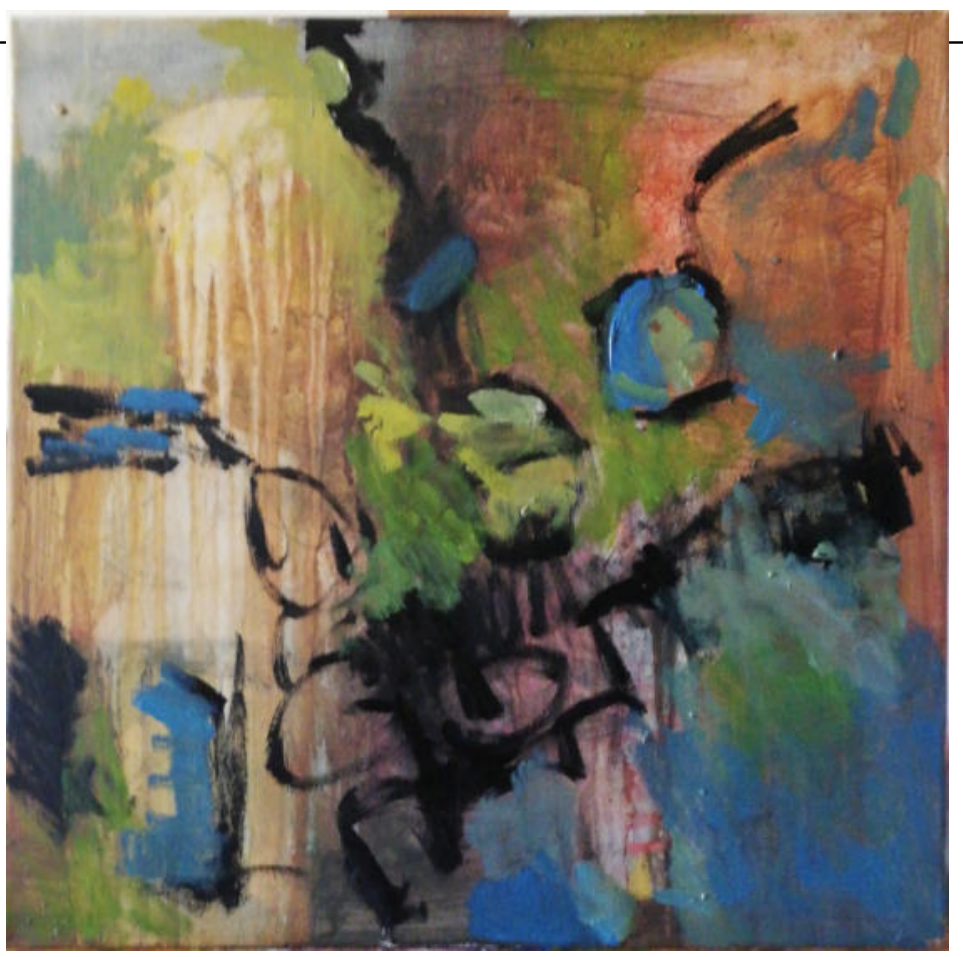

IISE

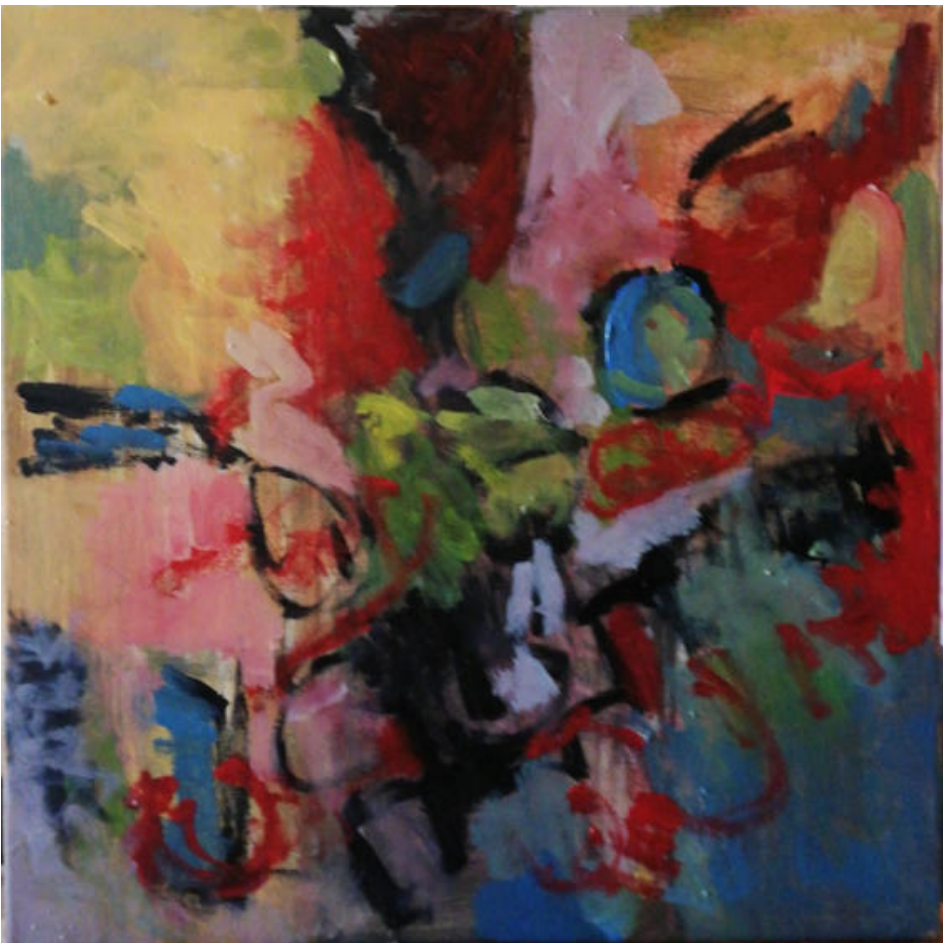

Figure 5. Re-Composing the Negative and Positive Spaces across the Canvas. 

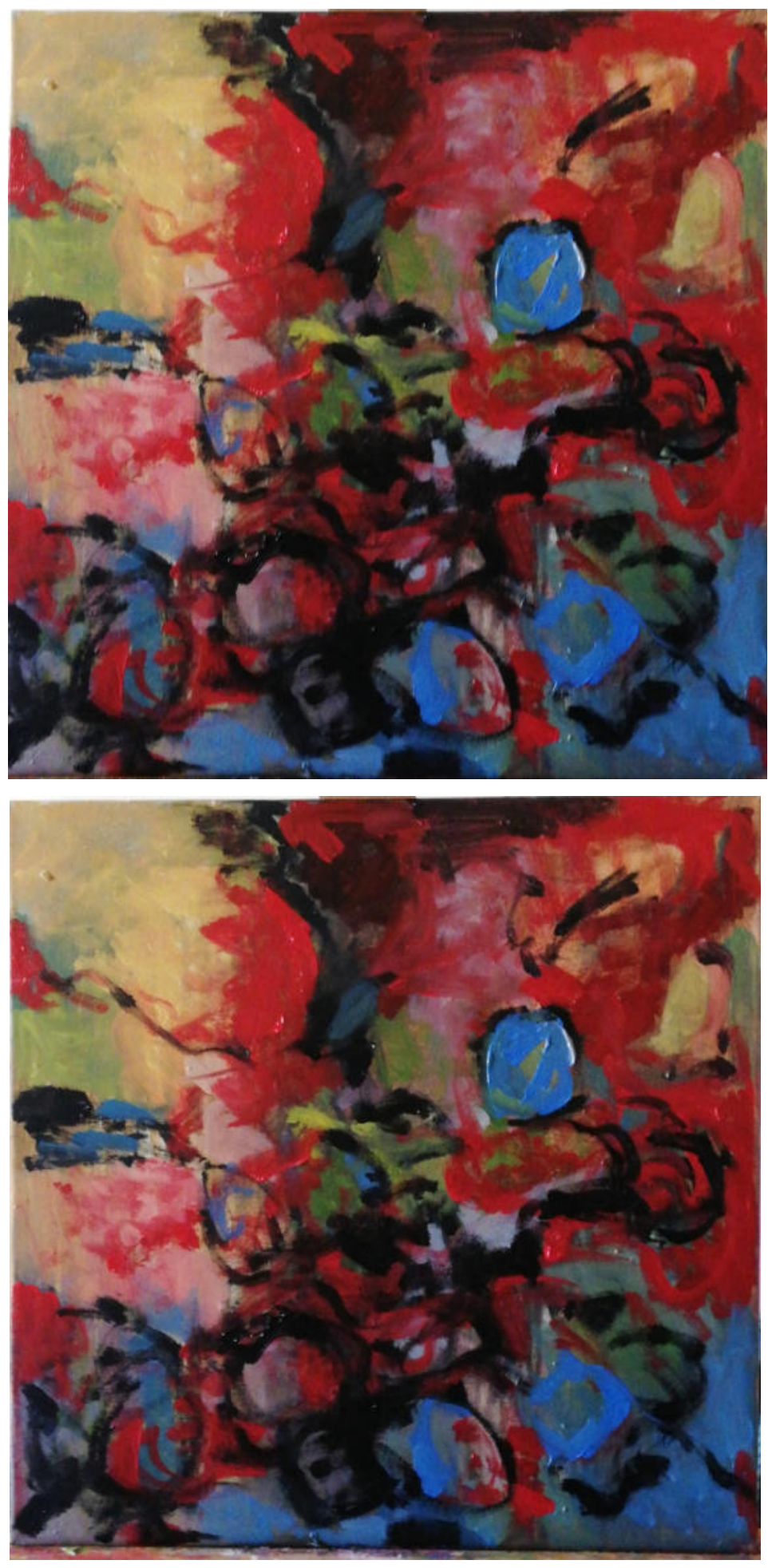

Figure 6. The Final Phases of the Painting. 


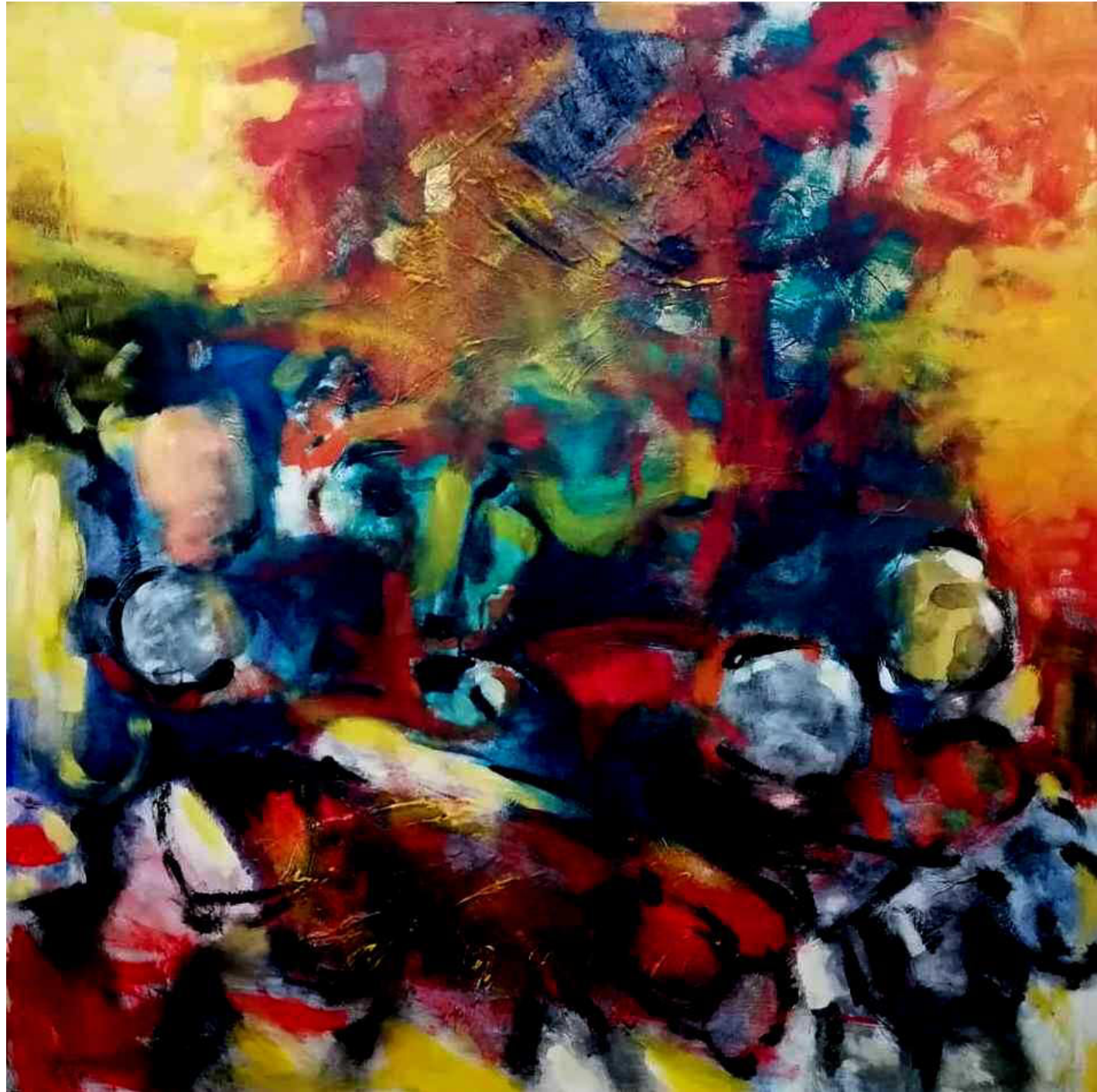

Fig. 7 People's Reflections in the City, 2018, 90 X 90 cm, mixed media and acrylic paints on canvas.

Within the spaces of this painting, Reflections of People in the City, the viewer observes the visual dominance and the strong presence of the dynamic human figure in the pictorial composition. This artwork portrays, in an expressive and abstract fashion, the human figure's manifestations through the visual and evocative expression of such an abstract beauty. The visually striking composition of this painting conveys the soundless touch of someone that relies on an individual colorful joy to express the movement of people and their visual turbulence in the overlapping urban spaces of the city.

Through the color schemes of this painting, the subjective feeling is comprehensive and deep, which prevails over the artist's (My) imaginative vision. This vision focuses on exposing the theme of artwork that overlaps the explicit visual details of the human form into its own spaces. This relationship between the human figurative form and its individual space, in the visual composition of this artwork, is based on manifesting a visual dialogue that achieves the impact of the visual wonder, which is visible through those bodies accumulating on both sides of the painting's balance.

The artistic practice, in the dramatic composition of this painting, aims to build a spatial diffusion of the figurative signs in order to dispense new spontaneous and automatic visual values that correspond and evoke the visual wonder in the eyes of the beholder in the contemporaneous city. These visual fragmentations and abstractions of the human figure are infusing within the urban architectural patterns of the city. Such artistic 
practice represents the aesthetic experiment with visual research.

Throughout this painting practice, the impression is creating a novel formulation of re-creativity within the people's contemporary cultural identity. The identity that is emerging into all these painted surfaces through the artwork composition to detect their dynamic visual elements that fuse the human morph with the urban structure of the city. This equation conceals the reality that traverses through the motives, arguments, symbolic and visual impressions of the painting practice. This reality transformed morphologically and spiritually to decorate the truth of people's selves into changing masks and spirits, so the false egos merge with pleasures and vanish with false identities.

Echoes of the dynamic abstract paintings composed visually aggressive memories and reflected the sensations of lost nostalgia in the new urban spaces of the cold city. The shadows of the ascending buildings fostered the expression of a vibrant self-dialogue that conferred different efficacious insights into the aesthetic practice. The everyday people of the foreign city wandered into the temporalities of the urban spaces, their hearts, and souls engaged effectively in the ascending city. The transcultural and traversing spaces of those contemporary cities accommodate people from diverse cultural backgrounds. Those people overlap into the layers of the cultural backdrops of the urban details. In this painting, the visual composition performed colorful particularities through the abstract reflections on the canvas surfaces. The artist/the author (I) produced a multilayered and visualized representational narratives of the transitive temporalities into the field of abstract expressions.

The artistic associations connected the abstract movement of the human bodies on the surface of the canvas with the cityscape created vibrant emerging masses of colors and lines. The fragmentation of the human mass into urban mass is the significant side of (my) artistic style. The balanced visual compositions developed a dramatic portrayal of the concrete memories that conceived the expression of actual and imagined narratives from the city spaces. The combinations of composition and visual intensities reproduced this significant diversity of abstract painting that represented the movements and the masses of the human bodies in constant and distinct abstract patterns, dimensions, symbolisms, and tones generated an artistic context that created a novel visible visual dialogue. The artworks generated a visually heavy association with the communal spaces and human urban realities. The reproduction of the human morphing figure within the visual composition manifests social and political values.

This artistic practice preformed an abstract figurative expressionist method to draw one critical side of the human social reality into the contemporary urban landscape. It engaged an aesthetic practice that exposed the significant integration between the human and the city employing pictorial visualization in painting. Abstract intensities of pictorial compositions, dynamic lines, brushstrokes, and volumes reflect the authenticity of human and urbanism into the common existing world. The artworks embody our participation in public and collective memory.

\section{Conclusion}

The impact of the otherness aesthetics on artistic practices manifested a novel diversity in the figurative expressionist painting, as individual artists display their creativity to the viewers in the displaying spaces such as exhibitions, biennales, and museums. The artists' imaginations traverse to fashionable drives of aesthetic comprehension, wherever their thoughts cultivated terrains to different individualities and novel conceptions toward contemporary arts. This synthesis of the creative practice identifies the visions and insights of the artists. Through which, visual culture connects to the aesthetics of the otherness into the academic relationships of the art and literature while a progressive fashion of congregating knowledge and art is being formed. This studiobased paper recorded artistic practice whiles the artist/the author himself was painting the artwork on $90 \mathrm{X} 90$ centimeters canvas with mixed media and acrylic paints, which is a hybrid painting technique. The paper focused on the ongoing creative action of painting figurative abstraction. This approach turned the artwork itself to be the primary source of this exploration, which negotiates the academic routine of citing and referencing throughout the written academic text. The present article is a practical and studio-based investigation, which resembles the artistic hybrid painting method conducted by the research-oriented artist/author (American Psychological Association, 2010); consequently, the practical approach does not limit the author/artist to cite secondary resources through the written textual context of the paper. Since the research is a documentative account of an expressionist painting. 


\section{References}

[1] American Psychological Association. (2010). Publication Manual of the American Psychological Association (6th ed.). Washington, DC: Author.

[2] Borgdorff, H. (2011). The Conflict of the Faculties: Perspectives on Artistic Research and Academia. Netherlands: Leiden University Press.

[3] Ficher- Rethus, L. (2004). Understanding Art ( $7^{\text {th }}$ ed). USA: Wadswarth/ Thomson learning.

[4] Gray C. \& Malins J. (2004) Visualizing Research: A Guide to the Research Process in Art and Design. Ashgate Publishing Limited: Hants, England.

[5] Grovier, K. (2015). Art Since 1989. New York: Thames and Hudson.

[6] Janson, H. w. (2007). Janson's History of Art ( $7^{\text {th }}$. Ed.). USA: Pearson Education, inc.

[7] Joo, E., Keehn II, J. \& Ham-Roberts, J. (2011). Rethinking Contemporary Art and Multicultural Education. New York: Routledge.

[8] Krausse, A. (1995). The Story of Painting from the Renaissance to the Present. Cologne: Konemann.

[9] Nanjo, F. (2006). Belief: Singapore Biennale 2006 (biennale catalogue, 4 September to 12 November, 2006). Singapore: National Art Council.

[10] Nanjo, F. (2008). Wonder: Singapore Biennale 2008 (biennale catalogue, 11 September to 16 November, 2008). Singapore: National Arts Council.

[11] Savin-Baden, M. and Wimpenny, K. (2014). A Practical Guide to Arts-related Research. Rotterdam, The Netherlands: Sense Publishers.

[12] Stokstad, Marjilyn.(2005). Art History (2ed. Ed.). USA: Pearson Education, inc.

[13] Walther,I. F. (2006). Impressionism (Michael Hulse, trans.). Germany: Taschen. 